Jurnal Keperawatan Silampari

Volume 5, Nomor 1, Desember 2021

e-ISSN: 2581-1975

p-ISSN: 2597-7482

DOI: https://doi.org/10.31539/jks.v5i1.2996

IPMERpe

\title{
PENGALAMAN KLIEN FILARIASIS DALAM MENJALANI PROGRAM PEMBERIAN OBAT PENCEGAHAN MASSAL (POPM)
}

\author{
Alpi Sri Rakhmayana ${ }^{1}$, Asniar $^{2}$, Elly Wardani $^{3}$ \\ Universitas Syiah Kuala, ${ }^{1,2,3}$ \\ asniar@unsyiah.ac.id ${ }^{2}$
}

\begin{abstract}
ABSTRAK
Penelitian ini bertujuan untuk mengekslorasikan pengalaman klien filariasis dalam menjalani program POPM di Kabupaten Pidie. Metode penelitian ini menggunakan metode penelitian kualitatif dengan pendekatan studi kasus. Hasil penelitian dari empat partisipan menunjukkan sembilan tema dan lima subtema. Tema (1) Mendapatkan manfaat simptomatik kemudahan finansial dan akses; mendapatkan manfaat simptomatik dan manfaat finansial dan kemudahan akses (2) Ketidakpatuhan menjalankan POPM (3) Mengkombinasikan dengan terapi komplementer (4) Keterbatasan aktivitas (5) Merasakan kelelahan (6) Menangani gejala akut dengan mencari pengobatan medis dan alternatif; pengobatan medis, herbal, dan berobat ke dukun (7) Menerima keadaan sakit dengan segala keterbatasan (8) Peran caregiver dijalankan oleh anggota keluarga (9) Penerimaan dan dukungan oleh masyarakat. Simpulan, klien mendapatkan manfaat simptomatik dan kemudahan finansial serta akses, adanya keterbatasan aktivitas, serta klien ketidakpatuhan dalam menjalani POPM, dan mencari pengobatan alternatif lain.
\end{abstract}

Kata Kunci: Klien Filariasis, Pengalaman, POPM

\section{ABSTRACT}

This study aims to explore the experience of filariasis clients undergoing the POPM program in Pidie Regency. This research method uses qualitative research methods with a case study approach. The study results of four participants showed nine themes and five sub-themes. Themes (1) Get symptomatic benefits of financial convenience and access; get symptomatic benefits and financial benefits and ease of access (2) Non-compliance with POPM (3) Combining with complementary therapies (4) Activity limitations (5) Feeling fatigued (6) Managing acute symptoms by seeking medical and alternative treatment; medical treatment, herbs, and treatment at a traditional healer (7) Accepting illness with all limitations (8) The role of caregiver is carried out by family members (9) Acceptance and support by the community. In conclusion, the client gets symptomatic benefits and financial convenience and access, activity limitations, and client non-compliance in undergoing $P O P M$ and seeking other alternative treatments.

Keywords: Filariasis Client, Experience, POPM

\section{PENDAHULUAN}

Filariasis adalah penyakit menular menahun yang disebabkan oleh cacing filaria dan ditularkan melalui nyamuk. Di Indonesia, cacing filaria terdiri dari tiga spesies yaitu wuchereria bancrofti, brugia malayi dan brugia timori. Penyakit ini menginfeksi jaringan 
limfe (getah bening). Filariasis menular melalui gigitan nyamuk yang mengandung cacing filaria dalam tubuhnya. Dalam tubuh manusia, cacing tersebut tumbuh menjadi cacing dewasa dan menetap di jaringan limfe sehingga menyebabkan pembengkakan di kaki, tungkai, payudara, lengan dan organ genital. WHO menetapkan kesepakatan global sebagai upaya untuk mengeliminasi filariasis pada tahun 2020 (The Global Goal of Elimination of Lymphatic Filariasis as a Public Health problem by The Year 2020). Saat ini di dunia terdapat 1,3 miliar penduduk yang berisiko tertular penyakit filariasis atau yang dikenal juga dengan penyakit kaki gajah yang berada pada lebih dari 83 negara dan $60 \%$ kasus berada di Asia Tenggara. Di Indonesia, pada tahun 2019 terdapat 10.758 kasus filariasis yang tersebar di 34 Provinsi. Angka ini terlihat menurun dari data tahun sebelumnya karena dilaporkan beberapa kasus meninggal dunia dan adanya perubahan diagnosis sesudah dilakukan konfirmasi kasus klinis kronis yang dilaporkan tahun sebelumnya (Kemenkes RI , 2019).

Secara nasional Provinsi Aceh tercatat atau berada di lima besar provinsi di Indonesia. Masih tingginya kasus filariasis karena banyaknya wilayah endemik di Aceh yang beresiko terhadap penularan dan penyebaran penyakit filariasis. Berdasarkan data Dinas Kesehatan Aceh di tahun 2019 mencapai 570 kasus dan tersebar di 23 kabupaten/kota. Kasus sebaran penyakit kaki gajah terbanyak berada di Kabupaten Aceh Utara dengan jumlah mencapai 92 kasus, Kabupaten Pidie 83 kasus, Aceh Timur 58 Kasus, dan Aceh Barat 14 kasus (Dinas Kesehatan \& Aceh, 2019).

Data yang peneliti dapat dari Dinas Kesehatan Pidie, mencatat dari Januari Desember 2019 terdapat 73 kasus (71 kasus lama dan 2 kasus temuan baru) filariasis yang tersebar di 9 puskesmas dari 26 puskesmas yang ada di Kabupaten Pidie dengan penderita filariasis terdiri 29 laki-laki dan 42 Perempuan dalam batas usia 15 tahun sampai di atas usia 60 tahun. Program yang sudah dilakukan adalah POPM pada Bulan Eliminasi Kaki Gajah (BELKAGA) pada bulan Oktober setiap tahunnya dan belum optimal (Profil Dinkes Pidie, 2019).

Kabupaten Pidie merupakan salah satu wilayah endemis filariasis dengan jumlah kasus klinis terbanyak di Provinsi Aceh. Pemberian obat pencegahan massal dimulai tahun 2011 -2015. Hasil penelitiannya menunjukkan bahwa, presentese yang cukupan penduduk yang minum obat dibandingkan dengan jumlah seluruh penduduk rata-rata $75,53 \%$, sedangkan cakupan yang penduduk yang minum obat dibandingkan dengan sasaran yang akan diberikan obat adalah rata-rata $87,3 \%$. Capaian ini memenuhi target yang diharapkan hasil survei awal pada tahun 2016 telah dilakukan uji Transmission Assesment Survey (TAS)-1 menggunakan Immunochromatographic Test (ICT) yang mana test ini digunkan untuk mendekteksi antigen dari W. Bancrofti dan hasilnya TAS-1 negatif (Ramadhan et al., 2020).

Penelitian yang dilakukan Nurjana et al., (2018) menyatakan bahwa peranan petugas kesehatan pada POPM filariasis yaitu penyediaan obat, sosialisasi, pelatihan hingga pendampingan saat pembagian obat di masyarakat sedangkan kader desa hanya membantu saat pembagian obat saja. Penelitian serupa tentang POPM juga dilakukan oleh Agustini et \& Indrwati (2020) yang mengungkapkan program POPM sudah dilaksanakan namun masih belum optimal, hal ini dapat dilihat sosialisasi sudah dilakukan, namun tingkat kesadaran dan pemahaman masyarakat tentang program POPM masih kurang. Pelatihan kader hanya dilakukan sekali menjelang pelaksanaan program. Serta belum adanya pengawasan atas obat yang diminum di rumah, untuk memastikan obat sudah diminum oleh sasaran. 
Penelitian yang dilakukan Muhammad (2019) tentang analisis kualitatif perilaku masyarakat terhadap pencegahan penyakit filariasis di desa Matang Pelawi Peureulak memperlihatkan pengetahuan masyarakat tentang pencegahan filariasis sebagian sudah faham, sebagian masyarakat bersikap negatif dengan mengejek, menghina dan menginginkan agar penderita filariasis diasingkan dari desa mereka karena dapat membawa musibah buruk bagi warga lainnya. Tindakan masyarakat sebagian paham tentang penyakit filariasis, dengan melakukan pencegahan seperti menjaga kebersihan lingkungan tempat tinggal, tidur menggunakan kelambu, dan minum obat pada Bulan Eliminasi Kaki Gajah (BELKAGA) pada bulan Oktober setiap tahunnya.

Penelitian yang dilakukan Ramadhan et al., (2020) menyatakan pasca POPM dan penilaian dengan TAS-1 di Kabupaten Pidie, ternyata masih ditemukan penderita positif mikrofilaria, hal ini berarti masih memungkinkan terjadinya transmisi filariasis. Pengetahuan responden tentang penyebab filariasis masih rendah, meskipun demikian adanya positif masyarakat akan pencegahan dan pengobatan filariasis, namun hanya Sebagian responden yang ikut terlibat dalam pengobatan massal. Namun sejauh ini belum ada data ataupun penelitian yang menguraikan bagaimana pengalaman klien filariasis dalam menjalani POPM tersebut, khususnya menggunakan pendekatan teori keperawatan adaptasi Roy yang mengkaji pengalaman klien dalam menjalani program Pemberian Obat Pencegahan Massal (POPM) di Kabupaten Pidie tahun 2020.

\section{METODE PENELITIAN}

Jenis penelitian yang digunakan adalah penelitian kualitatif, dengan pendekatan studi kasus (case study). Total sampel dalam penelitian ini adalah 4 orang partisipan dan dilakukan penelitian di Puskesmas Simpang Tiga di wilayah kerja Kabupaten Pidie pada bulan Januari-Februari 2021. Sampel dalam penelitian ini menggunakan teknik purposive sampling yaitu memilih beberapa partisipan sesuai dengan kriteria-kriteria. Kriteria partisipan adalah orang yang terinfeksi filariasis dan menjalani program Pemberian Obat Pencegahan Massal (POPM) yang mampu menceritakan pengalamannya selama menjalani POPM dan penelitian ini dilakukan di Kabupaten Pidie, didapat empat partisipan dan mau berpartisipasi dalam penelitian ini.

Instrumen utama dalam penelitian ini adalah peneliti sendiri, validasi penelitian dengan menggunakan wawancara yang mendalam pada partisipan yang sesuai dengan kriteria penelitian. Alat yang digunakan dalam penelitian ini adalah panduan wawancara, audio recorder (handphone), formular data demografi dan formular catatan lapangan (field note). Metode yang peneliti gunakan adalah observasi, wawancara mendalam dan dokumentasi serta percakapan secara informan. Pengumpulan data dilakukan langsung dan tidak langsung (dengan menggunakan via telpon). Peneliti mengkondisikan keadaan dan kesiapan waktu daripada partisipan, (keadaaan pandemik COVID-19). Peneliti tetap mengikuti protokol kesehatan COVID -19 di Kabupaten Pidie.

Pengambilan data pada setiap partisipan dengan menggunakan teknik wawancara terstruktur dan mendalam (in-depth interview) berdasarkan pendoman wawancara terstruktur yang berisi pertanyaan terbuka terkait tujuan penelitian yang akan dicapai. Hasil analisis tersebut kemudian diuraikan kualitatif untuk mendapatkan sebiah kesimpulan akhir. Penelitian ini menggunakan dua kategori partisipan yaitu key participant (partisipan utama) dan associate participant (partisipan pendukung). Partisipan pendukung terkadang memberikan informasi yang tidak diberikan oleh partisipan utama. Associate participant hanya membantu untuk mendukung data di lapangan yaitu perawat puskesmas penanggung jawab program filariaris. 
Key participant sebaiknya orang yang bersedia berbagi konsep dan pengetahuan dengan peneliti, dan sering dijadikan tempat bertanya oleh peneliti untuk mendapatkan gambaran yang utuh dan menyeluruh tentang masalah yang sedang diamati, key participant yaitu klien filariasis yang telah/sudah menjalani program POPM di Kabupaten Pidie, dapat menceritakan pengalamannya secara langsung dan sedang tidak menjalani program POPM untuk penyakit lainnya.

Sebelum melakukan wawancara atau mengumpulkan data peneliti menjalin hubungan saling percaya dengan setiap partisipan. Wawancara yang peneliti lakukan pada setiap partisipan dengan waktu yang telah disepakati oleh partisipan sebelumnya. Wawancara yang dilakukan 2-3 kali pertemuan dengan setiap partisipan (langsung dan via telpon) dengan durasi waktu 30-60 menit. Selanjutnya partisipan bersedia menandatangani lembar persetujuan untuk berpartispasi dalam penelitian ini. Setelah terkumpulkan data, kemudian data dianalisis menggunakan metode collaizi dalam yaitu suatu metode yang digunakan oleh peneliti yang melibatkan hasil observasi dan analisis perilaku individu dalam kesehariannya untuk menguji hasil pengalaman yang tidak bisa diungkapkan dengan kata-kata atau secara verbal.

Hasil wawancara direkam langsung dengan menggunakan Hp (tidak langsung). Validasi data langsung dilakukan oleh peneliti bila ada informasi yang kurang jelas dari jawaban masing-masing partisipan, dimana sebelumnya sudah mengkontrak waktu untuk pertemuan selanjutnya dengan partisipan. Pengambilan gambar/foto juga dilakukan peneliti sebagai bahan pendokumentasian dengan menggunakan $\mathrm{Hp}$ dan pengambilan data dihentikan bila sudah saturasi data, yaitu dimana tidak ada lagi data baru yang didapat.

\section{HASIL PENELITIAN}

Tabel. 1

Tujuan Khusus dan Tema

\begin{tabular}{|c|c|c|c|}
\hline No & Tujuan Khusus & Tema & Subtema \\
\hline 1 & $\begin{array}{l}\text { Mengetahui persepsi } \\
\text { klien filariasis }\end{array}$ & $\begin{array}{l}\text { Mendapatkan manfaat } \\
\text { simptomatik, kemudahan } \\
\text { finansial dan akses }\end{array}$ & $\begin{array}{ll}\text { a. } & \text { Mendapatkan } \\
& \text { manfaat } \\
& \text { simptomatik } \\
\text { b. } & \text { Mendapatkan } \\
& \text { manfaat finansial } \\
\text { dan kemudahan } \\
\text { akses }\end{array}$ \\
\hline 2 & $\begin{array}{l}\text { Mengetahui } \\
\text { bagaimana } \\
\text { pengalaman } \\
\text { klien filariasis }\end{array}$ & $\begin{array}{ll}\text { a. } & \text { Ketidakpatuhan } \\
& \text { menjalankan POPM } \\
\text { b. } & \text { Mengkombinasikan dengan } \\
& \text { terapi komplementer }\end{array}$ & - \\
\hline 3 & $\begin{array}{l}\text { Mengetahui } \\
\text { stressor klien } \\
\text { filariasis }\end{array}$ & $\begin{array}{l}\text { a. Keterbatasan aktifitas } \\
\text { b. Merasakan kelelahan }\end{array}$ & - \\
\hline 4 & $\begin{array}{l}\text { Mengetahui } \\
\text { adaptasi fungsi } \\
\text { fisiologis klien } \\
\text { filariasis }\end{array}$ & $\begin{array}{l}\text { Menangani gejala akut dengan } \\
\text { mencari pengobatan medis dan } \\
\text { alternatif }\end{array}$ & $\begin{array}{ll}\text { a. } & \begin{array}{l}\text { Pengobatan } \\
\text { medis }\end{array} \\
\text { b. } & \begin{array}{l}\text { Pengobatan } \\
\text { herbal }\end{array} \\
\text { c. } & \begin{array}{l}\text { Berobat ke } \\
\text { dukun }\end{array}\end{array}$ \\
\hline 5 & $\begin{array}{l}\text { Mengetahui adaptasi } \\
\text { konsep diri klien } \\
\text { filariasis }\end{array}$ & $\begin{array}{l}\text { Menerima keadaan sakit dengan } \\
\text { segala keterbatasan }\end{array}$ & - \\
\hline
\end{tabular}




\begin{tabular}{llll}
\hline 6 & $\begin{array}{l}\text { Mengetahui adaptasi } \\
\text { fungsi peran klien } \\
\text { filariasis dalam } \\
\text { menjalani POPM }\end{array}$ & $\begin{array}{l}\text { Peran caregiver dijalankan oleh } \\
\text { anggota keluarga }\end{array}$ \\
\hline 7 & $\begin{array}{l}\text { Mengetahui adaptasi } \\
\text { interdependensi klien }\end{array}$ & $\begin{array}{l}\text { Penerimaan dan dukungan oleh } \\
\text { masyarakat }\end{array}$ & - \\
& $\begin{array}{l}\text { filariasis dalam } \\
\text { menjalani POPM }\end{array}$ & \\
\hline
\end{tabular}

Penelitian ini menghasilkan sembilan tema, yaitu mendapatkan manfaat simptomatik, kemudahan finansial dan akses pengobatan, ketidakpatuhan menjalankan POPM, mengkombinasikan dengan terapi komplementer, keterbatasan aktivitas, merasakan kelelahan, menangani gejala akut dengan mencari pengobatan medis dan alternatif, menerima keadaan sakit dengan segala keterbatasan, peran caregiver dijalankan oleh anggota keluarga, dan penerimaan dan dukungan oleh masyarakat.

\section{Tema 1: Mendapatkan Manfaat Simptomatik, Kemudahan Finansial dan Akses}

Tema ini menjelaskan tentang partisipan mempersepsikan POPM sebagai program yang memberikan manfaat mengurangi atau mengontrol gejala, serta memberikan kemudahan finansial berupa obat yang gratis, serta kemudahan akses dalam mendapatkan obat. Berikut ungkapan dari partisipan:

"Alhamdulillah... saya pribadi senang, karena dapat membantu penyakit kaki saya, setidaknya dapat mengurangi tidak tambah besar, masih bisalah melakukan kegiatan sehari-hari seperti biasa" (Partisipan 1)

"baik, senang saya, karena ada obat dari puskesmas dan obatnya gratis, karenakan bu obat itu tidak dijual di apotik dan ke dokter juga gak ada...Alhamdulillah, semoga ke depan ada obat itu lagi" (Partisipasi 4)

"ada kurang pertama-tama berobat, kalau minum obat nampak kurang ukurannya, kalau tidak minum kembali seperti semula. tidak sampai sembuh" (Partisipasi 2).

"oh. baik. senang kita, karena itu sangat membantu apalagi saya bisa mendapatkan obat kaki yang gratis, kalaupun ada dijual belum tentu saya sanggup trus tuk membelinya, Alhamdulillah, semoga dikasih lagi" (Partisipasi 3)

\section{Tema 2: Ketidakpatuhan Menjalankan POPM}

Tema ini menjelaskan seluruh partisipan tidak patuh dan melakukan kombinasi dengan melakukan pengobatan herbal dan mencari alternatif dalam menjalani POPM. Berikut ini ungkapan dari partisipan:

"pertama - tama enak setelah minum obat kaki gajah itu. karena saya juga ada minum obat darah tinggi, kalau lagi kambuh darah tinggi saya, ya saya minum obat darah tinggi. ada minum, tapi tidak teratur, karena saya ada minum obat lain, lagi sakit perut minum obat sakit perut, obat kaki gajah tidak saya minum takut nanti ada efeknya ke tubuh.... bapak saya sendiri (Almarhum), waktu saya gadis dulu, dibawa kesana sini untuk berobat, semua obat sudah pernah, sampek berobat ke dukun pun sudah pernah." (Partisipan 1)

"ya teratur saya minum, kalau lagi sakit kepala saya berhenti sebentar saya minm obat sakit kepala...takuut kita campur-campur obat! Hai.ada perubahan dikit disaat itu, jarang kambuh-kambuh sakit, kalau kambuh tidak sampai berat demam, dan panas di kaki. ini sekarang tidak ada obat lagi.hai, kita tarok minyak, kadang-kadang minyak 
rambut, kelapa, kadang saya olesin daun pepaya yang dikeringkan dan sudah ditumbok (dihaluskan) gak kunjung sembuh juga," (Partisipan 2)

"Tapi kalau lagi minum obat kaki gajah, dan tidak lagi kambuh, hai setelah minum obat itu seminggu sudah sembuh nyerinya. ya ada saya minum. gimana yang di kasih resep begitu saya minumnya gitu). gak sampai habis minum obatnya. karena ada batas obat, baik obat dari dokter sini maupun dokter lain. dua kali sehari, pagi dan malam, jangan banyak kali obat sendiri he...he" (Partisipasi 3)

"Cuma sekali itu... he.hee.... menyesal juga kenapa saya bandel gak mau minum rutin. Oh yang itu ada dapat dan ada saya minum. Habis saya minum. kalau sudah lama ada demam, ada 6 bulan sekali dia kambuh, malam minum obat, saya minum obat dari mentri-mentri kampung gitu tidak pergi berobat ke puskesmas. Sudah kek gitu aja hee..he,,he,,karena tidak ada obat itu dijual disana...biasa saja..tidak ada perubahan kuran kaki saya ada juga disarankan obat oles di kaki, pernah saya pakek cuma sebulan, tidak saya lanjut lagi. diolesin minyak sama anak, panas dan nyerinya berkurang dan hilang. rasa penyesalan ada karena dulu tidak minum obat yang dikasih oleh perawat puskesmas" (Partisipasi 4).

\section{Tema 3: Mengkombinasikan dengan Terapi Komplementer}

Tema ini menjelaskan tentang selama menjalani POPM yang diberikan setiap satu tahun sekali, karena tidak memberikan kesembuhan dan tidak ada perubahan yang signifikan, semua partisipan melakukan pengobatan lain. Berikut ungkapan dari setiap partisipan:

"Ada sedikit, tapi saya ada pergi terapi berobat juga di tempat lain” (Partisipan 1) “... hai, kita tarok minyak, kadang-kadang minyak rambut, kelapa, kadang saya olesin daun pepaya yang dikeringkan dan sudah ditumbok (dihaluskan).. kadang-kadang berobat dibawa ke pasi (pantai) untuk ditanam kakinya.dan ada perubahan" (Partisipan2)

"sekarang enggak minum obat, Cuma tarok minyak dikaki dulu tarok obat herbal dan pakai obat-obat kampung. Obat-obat kambuh seperti daun pik ular... nanti orang itu datang kerumah dan mengoleskan obat herbal dan tradisional yang dibawa orang tersebut, bahkan sampai kotoran kerbau pernah saya tarok di kaki" (Partisipan 3)

"ada juga pergi ke dokter, pergi ke dukun lain dibilang, misal ada pergi atau lewat kuburan sipulan, kalau kita pergi berobat ke tempat lain-lain lagi dibilang ini ada pergi ke hutan ya.... ada juga disarankan obat oles di kaki, pernah saya pakek cuma sebulan, tidak saya lanjut lagi., banyak ada yang suruh tarok air beras dengan taik cacing pita, ada saya tarok sekali dan nampak berkurang, tapi itulah Cuma sekali saya tarok" (Partisipan 4)

\section{Tema 4: Keterbatasan Aktivitas}

Tema ini menjelaskan tentang keterbatasan aktivitas dikarenakan sakit dikaki dan kambuh disaat banyak jalan dan beraktivitas berlebihan membuat partisipan menjadikan stressor dalam menjalani aktivitas sehari-hari. Berikut ungkapan dari partisipan.

"sakit kalau lagi kambuh aja, itu baru tidak bisa jalan kambuh biasanya kalau sudah kecapean atau banyak jalan. hai emm. bengkaknya masih seperti semula, tidak nampak berkurang badan demam, panas di kaki kemerah-merahan pahanya... minum obat demam, tarok minyak agar dingin paha yang kemerahan tadi... kadang tarok obat kampung di paha biar dingin pahanya" (Partisipan 1)

"kayaknya banyak jalan atau saya kecapean, misalnya dulu saya ada ke sawah, itu sering kambuh" (Partisipan 2) 
"saya masih bisa melakukan kegiatan sehari-hari sendiri. Kalau seringan jalan-jalan itu baru terasa sakitnya.... ini sakit baraticak, dari selangkangan paha turun ke kaki sudah bengkak kakinya. sakit nyeri berdenyut-denyut, dan panas di kaki yang bengkak...ya mulai dari kaki merasa panas, tapi Alhamdulillah tidak kejang-kejang, membengkak ada, sampek kemerahan" (Partisipan 3)

"Tidak boleh banyak jalan-jalan cepat kambuh. Malam-malam tidak boleh bergadang. Waktu saya lama jalan baru nampak besar dikit kakinya. demam, ada 6 bulan sekali dia kambuh tidak ada perubahan sama saja ukurannya...kadang besar dikit nanti balek lagi, tergantung banyak gerak dan tidak boleh capek karena bisa kambuh sakitnya" ( Partisipan 4)

\section{Tema 5: Merasakan Kelelahan}

Tema ini menjelaskan tentang partisipan merasakan stressor dalam menjalani POPM dan mempengaruhi kegiatannya sehari, tidak bisa melakukan aktivitas berlebihan cepat merasakan kecapean dan lelah. Partisipan dalam penelitian ini menyebutkan bahwa:

"sakit kalau lagi kambuh aja, itu baru tidak bisa jalan. kambuh biasanya kalau sudah kecapean atau banyak jalan. Emm.. bengkak ya masih seperti semula, tidak nampak berkurang.. minum obat demam, tarok minyak agar dingin paha yang kemerahan tarok obat kampung biar dingin pahanya" (Partisipan 1)

"banyak jalan saya kecapean, misalnya dulu saya ada ke sawah, itu sering kambuh" (Partisipan 2)

"saya masih bisa melakukan kegiatan sehari-hari sendiri. Kalau seringan jalan-jalan sudah capek itu baru terasa sakitnya, dari selangkangan paha turun ke kaki sudah bengkak kakinya sakit kadang-kadang nyeri berdenyut-denyut, dan panas di kaki yang bengka tidak tahu ada perasaan gimana-gimana... Sakit kadang-kadang nyeri berdenyut-denyut, dan panas di kaki yang bengkak ...ya mulai dari kaki merasa panas," (Partisipan 3)

"tidak tentu, kalau kita sudah capek kali baru terasa sakit. Tidak boleh banyak jalan bisa cepat kambuh. malam-malam tidak boleh bergadangcepat panas di kaki...Tidak ada perubahan sama saja ukurannya, kadang besar dikit nanti balek lagi, tergantung kita banyak jalan gitu dan tidak boleh capek karena bisa kambuh sakitnya" (Partisipan 4).

\section{Tema 6: Menangani Gejala Akut dengan Mencari Pengobatan Medis dan Alternatif}

Tema ini menjelaskan tentang selama menjalani pengobatan POPM, partisipan mengatasi gejala akut dengan melakukan pengobatan secara herbal dan medis. Berikut ungkapan dari partisipan:

"ada perubahannya dikit. Tidak tambah besar kakinya sama kek tadi saya bilang tidak ada perubahan ukuran jadi kecil gitu (normal kembali) ada..ya lihat kondisi tubuh dulu, kalau sehat baru kita pergi, pergi kek biasa juga, badan demam, panas di kaki kemerahmerahan pahanya kalau sudah berkurang kulitnya terkelupas. sakit nyeri sekali-kali di kaki kalau lagi kambuh... minum obat demam, tarok minyak agar dingin paha yang kemerahan tadi. kadang tarok obat kampung daun pepaya yang ditumbuk di paha biar dingin pahanya" (Partisipan 1)

" ya begitu bengkak terus kakinya... nyeri, demam, panas di kaki.. minum obat demam, sembuh sakitnya. hilang demamnya! hai ,kita tarok minyak, kadang-kadang minyak rambut, kelapa, kadang saya olesin daun pepaya yang dikeringkan dan sudah ditumbok (dihaluskan)" (Partisipan 2) 
"hai.. tarok obat, apa yang mungkin , obat-obat kampung apa yang orang bilang... Masih, kadang-kadang terasa nyeri di benjolan pada selengkagan paha, setelah itu demam, ke dokter, dikasih obat demam....ya mulai dari kaki merasa panas, cuma demam saja pada kaki bengkak, sampek kemerahan gitu, dan panas di kaki yang bengkak... tarok minyak kelapa biar dingin... gak ingat lagi..dulu tarok obat herbal dan pakai obat-obat kampung. seperti daun pik ular" (Partisipan 3)

"hai, saya merasa heran juga bengkaknya makin besar, karena saya tidak ada tumbuh benjolan di bagian lipatan paha, tiba-tiba bengkak .... kalau sudah lama ada demam, ada 6 bulan sekali dia kambuh, malam minum obat, saya minum obat dari mentri-mentri kampung gitu tidak pergi berobat ke puskesmas ...banyak ada yang suruh tarok air beras dengan taik cacing pita" (Partisipan 4).

\section{Tema 7: Menerima Keadaan Sakit dengan Segala Keterbatasan}

Tema ini menjelaskan tentang partisipan dapat menerima kondisinya dan mengganggap penyakitnya merupakan takdir dari yang Maha Kuasa dan menjalankan aktivitasnya seperti biasa serta tetap berusaha berobat. Partisipan dalam penelitian ini menyebutkan:

"Baik iya. baik kita hidup dalam masyarakat mana boleh sombong...ada. ya lihat kondisi tubuh dulu, kalau sehat baru saya pergi, Alhamdulillah tidak pernah, saya biasa saja karena yakin sakit saya pun tidak menganggu orang lain cuma bengkak saja yang masih nampak ya ..itu sudah menjadi takdir saya"(Partisipan 1)

"Saya tinggal sendiri nak! Sekali-kali nanti datang anak dan cucu ke rumah baik, sama sekali saya tidak terganggu aktivitas, saya juga tidak malu, saya menerima apa yang Allah kasih ke saya, kalau pertama-tama pastilah payah untuk diterima, tapi itu dulu kali. He.hee" (Partisipan 2)

"kalau saya pribadi enggak putus asa, karna udah sakit ya minum obat kapan sembuhnya kita gak tau semua pemberian dari Allah, kita usaha saja untuk berobat.... ada rasa sedih kadang-kadang, apalagi saat kambuh sakit kali, tapi saya yakin pasti sembuh. Dan saya menerima apa yang Allah kasih ke saya, masih ada orang yang lebih berat sakitnya, saya masih bisa melakukan kegiatan sehari-hari sendiri... kita serahkan semua pada Allah" (Partisipan 3)

"hai kita mikirin yang tidak perlu kita pikirin, yang ada nambah sakit yang lain, kalau kek saya cuek aja nah! saya yakin, Allah yang beri sakit maka Allah jua yang menyembuhkannya, kita wajib berusaha, dan kita berdoa semoga mustajab/dikabulkan setiap usaha kita. ngapain buang-buang waktu untuk apa kita berputus asa atas kehendak Allah, iyakan!" (Partisipan 4)

\section{Tema 8: Peran Caregiver Dijalankan oleh Anggota Keluarga.}

Tema ini menjelaskan tentang selama menjalani POPM filariasis keluarga selalu membantu dalam melakukan perawatan seperti mengoleskan obat/ramuan di kaki, membawa berobat pada partisipan dengan harapan partisipan bisa sehat dan normal kembali seperti semula. Partisipan dalam penelitian menyebutkan bahwa:

"Saya sendiri, kalau sanggup kerjain sendiri, kalau tidak dibantu sama anak, masak nasi dikit kadang-kadang sampek malam saya cuma tinggal berdua sama anak (sambil ketawa)...., kalau dulu ada waktu masih gadis ada, sekarang sudah tua, lihat-lihat kerja anak muda saja, sekarang ganti anak saya yang ikut terlibat kegiatan di kampung... iya, dibantu anak saya yang buat dan sering juga saya yang buat dia yang tarok obat kalau saya sakit, saya tinggal berdua sama anak ya dia yang bantu rawat saya" (Partisipan 1) 
"Kalau dulu masih muda, saya pergi sendiri kerana anak-anak pada saat itu masih kecil...ada juga dulu dibawa suami, karena sekarang anak-anak sudah besar, mereka yang bawa saya berobat, kadang-kadang cucu saya ikut bawa saya berobat atau antar saya ke suatu tempat misal orang meninggal, kenduri... Saya tinggal sendiri nak! Sekalikali nanti datang anak dan cucu ke rumah (Partisipan 2)

"bisa, kadang-kadang di bantu sama anak untuk bangun, jalan bisa sendiri, sekarang saja pakek tongkat karena sudah tua. Masih bisa melakukan kegiatan di rumah sendiri"'(partisipan 3)

"oh..tidak, seperti biasa kalau dirumah jadi ibu rumah tangga, jualan di kios dikit, cuci baju ya kek ibu lihatlah. Tidak menganggu aktivitas saya kecuali lagi kambuh saja kalau sudah kecapaen, itulah kalau kambuh kek saya bilang tadi ibu, semua orang rumah jadi sibuk, anak suami yang bantu keperluan di rumah"(Partisipan 4)

\section{Tema 9: Penerimaan dan Dukungan oleh Masyarakat}

Tema ini menjelaskan tentang dengan adanya dukungan keluarga dari masyarakat setempat dengan selalu melibatkan partisipan dalam berbagai acara di kampung, tidak mengucilkan, dan tidak memberi stigma yang negatif partisipan merasa selalu dihargai,dan dihormati di lingkungan tempat tinggalnya.

Partisipan dalam penelitian ini menyebutkan bahwa:

"Baik...Alhamdulillah tidak ada perubahan dari masyarakat., maka sering diminta bantu atau mengantikan seseorang, Seperti kek mimpin tahlilan, bawa siri (Batee ranup) waktu serah terima linto baro dara baro, Alhamdulillah baik dengan masyarakat... keluarga.. bapak saya sendiri (Almarhum), waktu saya gadis dulu, dibawa kesana sini untuk berobat" (Partisipan1)

"ha..ha.. hai ada juga, Hai ada juga dibilang, dari kawan-kawan, di radio banyak iklaniklan tuk berobat, tidak perlu orang juga lain bilang. Kadang-kadang ada yang bagus, tapi banyak orang yang rajin pergi berobat gak sembuh juga, jadi malas kita pergi lagi"'(Partisipan2)

"Masih, sampai sekarang pun kalau ada undangan kenduri saya tetap ikut hadir sebagaimana biasanya aja gitu. Biasa saja tidak yang berubah, kita tinggal dikampung salaing mengunjungi satu sama lain.. Baik-baik aja, kalau ada kenduri-kenduri selalu terlibat, diajak untuk bantu masak-masak, masyarakat tetap baik" (Partisipan 3)

"Baik-baik saja, Insya Allah masyarakat kampung kami itu banyak orang berpendidikan semua, tidak suka meremehkan orang lain, kami saling menghargai dan mengunjungi saat ada warga yang sakit dan memberikan perhatian.. Ada, kalau banyak disarankan pergi berobat ke suatu tempat saya iayakan saja dulu, biar mereka tidak tersinggung tapi saya tidak mau berobat ke sembarang tempat, takuut saya.he..he.he”.(Partisipan 4).

\section{PEMBAHASAN}

\section{Mengetahui Persepsi Klien Filariasis terhadap POPM}

Dari hasil penelitian tentang persepsi klien dalam menjalani POPM tema klien mendapatkan manfaat simptomatik, kemudahan finansial dan akses, terdiri dari 2 subtema, yaitu; 1) mendapatkan manfaat simptomatik dan 2) mendapatkan manfaat finansial dan kemudahan akses. Efektifitas kemudahan dalam akses-akses untuk proses pengobatan dalam mencegah penyebaran filariasis.

Pemerintah Indonesia telah mencanangkan beberapa program pelayanan kesehatan untuk menciptakan kondisi kesehatan masyarakat agar menjadi lebih baik. Programprogram tersebut antara lain berupa subsidi pembiayaan kesehatan, dimana biaya 
dibebankan pada anggaran pemerintah daerah atau sumber dana lain yang sesuai dengan peraturan yang berlaku. Peningkatan sumber daya manusia di sektor kesehatan, peningkatan sumber daya obat dan perbekalan kesehatan, pemberdayaan masyarakat, serta perbaikan manajemen kesehatan (Kementerian Kesehatan RI, 2018).

\section{Mengetahui Pengalaman Klien Filariasis dalam Menjalani POPM}

Hasil penelitian dari pengalaman klien filariasis dalam menjalani POPM, didapatkan tema ketidakpatuhan partisipan dalam menjalankan POPM dan mengkombinasikan dengan terapi komplementer. Pembentukan sikap dipengaruhi oleh beberapa faktor, yaitu pengalaman pribadi, kebudayaan, orang lain yang dianggap penting, media masa, institusi atau lembaga pendidikan dan lembaga agama, serta faktor emosi dalam diri individu. Sikap merupakan langkah utama seseorang untuk bertingkah laku, sikap yang benar akan berefek pada tingkah laku yang benar pula, dalam pengendalian filariasis sikap responden yang positif akan berpengaruh terhadap upaya pengendalian faktor risiko penularan filariasis (Tallan et al., 2019).

Analisis perilaku masyarakat dalam kegiatan POPM di Kecamatan Majalaya Kabupaten Bandung menunjukkan bahwa praktik masyarakat tentang pencegahan, pengendalian dan pengobatan filariasis secara signifikan berhubungan terhadap kepatuhan masyarakat untuk minum obat. Perilaku praktik minum obat secara langsung berkontribusi terhadap target cakupan pemberian obat massal pencegahan filariasis. Namun demikian perilaku kepatuhan minum obat tidak berdiri sendiri, kondisi ini terkait erat dengan dukungan Sumber Daya Manusia (SDM) baik petugas kesehatan, kader, lintas sektor dan gencarnya promosi melalui berbagai media promosi tentunya (Muhammad, 2019).

Pengobatan komplementer adalah pengobatan non konvensional yang ditujukan untuk meningkatkan derajat kesehatan masyarakat meliputi upaya promotif, preventif, kuratif dan rehabilitatif yang diperoleh melalui pendidikan terstruktur dengan kualitas, keamanan dan efektivitas yang tinggi berlandaskan ilmu pengetahuan biomedik akan tapi belum diterima dalam kedokteran konvensional. Munculnya kebosanan pada pasien yang tidak kunjung sembuh menjadi alasan bagi mereka untuk mencari pengobatan komplementer yang dirasa dapat memberikan kenyamanan fisik dan mental. Dalam penelitian tentang terapi komplementer, mayoritas menggunakan jenis produk herbal daripada jenis lainnya. Berbagai macam cara digunakan oleh responden dalam pengolahan produk herbal, seperti direbus, dikunyah langsung, dijemur, dibuat olahan sayur dan sebagainya (Husnati et al., 2017).

Dari uraian di atas peneliti berasumsi bahwa partisipan yang berobat ke puskesmas hanya mendapatkan obat simptomatis untuk mengurangi keluhan nyeri. Partisipan yang menggunakan obat herbal dengan harapan dapat meningkatkan stamina, dan partisipan yang tidak lagi mencari pengobatan dengan alasan sakit itu sudah biasa dan akan sembuh dengan sendirinya bila diistirahatkan. Partisipan yang pernah diberikan dan minum obat filariasis, partisipan dianjurkan untuk rutin berobat tapi masih saja dikombinasikan dengan obat lain, dikarenakan ada rasa bosan tidak kunjung sembuh maka partisipan mencari pengobatan lain.

\section{Mengetahui Stressor Klien Filariasis dalam Menjalani POPM}

Hasil penelitian stressor pada klien filariasis selama menjalani POPM didapatkan dua tema yaitu; a) keterbatasan aktivitas dan b) merasakan kelelahan. Berdasarkan hasil penelitian seluruh partisipan mengungkapkan pernah mengalami gejala fisik berupa banyak bergerak dan berjalan mengakibatkan rasa sakit (kambuh) seperti rasa panas, merah, 
bengkak, demam dan cepat merasakan capek di saat melakukan aktivitas berlebihan. Dampak negatif yang sering dirasakan partisipan adalah tidak merasa bebas karena sulit berjalan dan tidak dapat beraktivitas sehari-hari (Reasoa et al., 2020).

Berdasarkan uraian di atas, maka peneliti berasumsi serangan berulang pada partisipan terjadi karena kecapean atau setelah bekerja berat, hai ini diungkapkan oleh empat partisipan dengan ungkapan yang berbeda diantaranya, penyakit kambuh setelah bekerja di sawah, setelah naik turun tangga, perjalanan jauh dan capek mengerjakan pekerjaan di rumah. Hal ini terjadi karena dengan kecapean atau kerja berat dapat meningkatkan respon immun, yang dapat meningkatkan pelepasan mediator inflamasi sehingga gejala nyeri dan demam sering terjadi berulang kali karena kelelahan.

\section{Mengetahui Adaptasi Fungsi Fisiologis dalam Menjalani POPM}

Hasil penelitian yang berkenaan dengan tema menangani gejala akut dengan mencari pengobatan medis dan alternatif, terdiri dari 3 sub tema, yaitu pengobatan medis, pengobatan herbal dan berobat ke dukun. Selama menjalani program POPM dalam mengatasi gejala akutnya partisipan melakukan pengobatan secara herbal seperti mengoleskan ramuan daun yang dihaluskan pada kaki, pergi ke mantri, ke puskesmas dan ke dokter akan tetapi obat yang didapat bersifat simptomatik untuk penghilang nyeri.

Emosi adalah perasaan yang muncul ketika seseorang mendapatkan tekanan atau hal yang mengejutkan, begitu juga dengan penderita filariasis kronis yang bertahun-tahun hidup dengan kondisi cacat pada bagian tubuh, yang mermpengaruhi emosinya tidak stabil dimana merasakan kecewa, sedih, pasrah dan bahkan malu. Perasaan kecewa karena tidak ada perubahan ke arah yang lebih baik dengan meminum obat makanya mereka alternatif lain seperti mencari pengobatan tradisional (Ulfiana \& Indarjo, 2021).

Dari uraian di atas maka peneliti berpendapat bahwa semua partisipan telah datang ke tempat pelayanan kesehatan dan melakukan pengobatan ke pelayanan kesehatan, baik rumah sakit, puskesmas, praktik dokter swasta maupun praktik perawat, seluruh partisipan memilih untuk mencari pengobatan alternatif, mulai dari pengobatan dengan obat tradisional maupun pergi ke dukun. Semua partisipan mengungkapkan pernah mencari pengobatan ke dukun dengan harapan bisa cepat sembuh. Partisipan menggunakan obat herbal, obat dari dukun, dan mencari pengobatan walaupun sakitnya kambuh, karena dapat menghilangkan rasa nyeri dan panas di kaki walau sebentar.

\section{Mengetahui Adaptasi Konsep Diri dalam Menjalani POPM}

Hasil penelitian dari adaptasi konsep diri dalam menjalani POPM pada klien filariasis adalah menerima keadaan sakit dengan segala keterbatasan. Gangguan fisik pada klien filariasis mempunyai dampak yang sangat besar terhadap psikologis klien yang dapat mengganggu pembentukan konsep dirinya. Namun, semua partisipan sudah pasrah dan dapat menerima keadaanya serta menganggap ini merupakan takdir dari yang Maha Kuasa. Menurut WHO terkait dengan aspek sosial, beban psikologis juga mempengaruhi kehidupan pasien, biasanya orang depresi, sikap pasif, putus asa, dan fatalisme, dalam beberapa kasus bahkan mengarah ke bunuh diri (World Health Organization, 2017).

Respon psikososial penderita filariasis dalam kaitannya untuk mencapai kesejahteraan psikologis, seperti tidak dikucilkan, optimis, dampak negatif, dan hubungan sosial. Kecacatan yang dialami partisipan mengakibatkan dirinya harus hidup dengan ketergantungan terhadap orang lain dan mendapat perlakuan negatif dari lingkungan. Walaupun dampak tersebut harus dialami setiap harinya, partisipan tetap dapat mencapai kesejahteraan psikologis, terutama Ketika mereka menyadari bahwa ia tidak dikucilkan oleh 
lingkungannya, sehingga memunculkan adanyan rasa optimal. Hal ini menjadika partisipan tetap mampu dan terus berupaya untuk menjalin relasi sosial dengan lingkungannya yang lebih luas (Reasoa et al., 2020).

Dari uraian di atas peneliti berasumsi bahwa dengan menerima keadaan sakit dengan segala keterbatasan pada keempat partisipan menjadikan hidup lebih ringan dan mudah dalam menjalani kehidupan sehari-hari dan tetap percaya diri dalam berinteraksi dengan lingkungan sekitar. Menerima keadaan dengan segala keterbatasan bukan berarti menjadikan partisipan cepat berputus asa dalam berobat, menerima keadaan karena merupakan takdir dari Allah dan tetap menjalani pengobatan dan semakin termotivasi terus untuk berobat karena, bagi partisipan berusaha dan ikhtiar itu mendatangkan pahala dari Allah kalau dijalani dengan ikhlas.

\section{Mengetahui Adaptasi Peran Diri dalam Menjalani POPM}

Hasil penelitian dari adaptasi peran diri dalam menjalani POPM didapatkan tema peran caregiver dijalankan oleh anggota keluarga bahwa dalam keadaan akut yang paling parah terkena dampak adalah mobilitas, partisipan tidak bisa berjalan atau bergerak dan hanya terbatas. Partisipan sangat tergantung pada keluarga untuk perawatan dirinya disetiap kambuh gejala akutnya maka partisipan akan merasakan demam, bengkak, nyeri dan warna kemerah-merahan di area bengkak tersebut. Kemampuan adaptasi family caregiver yang meliputi sikap, kepercayaan, dukungan keluarga, fungsi peran, mekanisme koping dan kemampuan adaptasi family caregiver (Indarwati et al., 2020).

Hasil penelitian yang dilakukan oleh Afiyah (2018) menunjukkan bahwa dukungan keluarga berpengaruh terhadap kemampuan adaptasi. Apabila dukungan keluarga baik, maka pasien akan mudah beradaptasi dengan penyakitnya. Sebaliknya, apabila dukungan keluarga kurang, maka pasien akan sulit beradaptasi dengan penyakitnya. Bentuk dukungan yang diberikan tidak berupa saran, nasehat, atau support saja, namun berupa tindakan nyata dengan mengontrol, menjadwal, dan mendampingi ketika menjalani serangkaian pengobatan kanker. Menunjukkan bahwa dukungan keluarga berpengaruh terhadap kemampuan adaptasi. Apabila dukungan keluarga baik, maka pasien akan mudah beradaptasi dengan penyakitnya. Sebaliknya, apabila dukungan keluarga kurang, maka pasien akan sulit beradaptasi dengan penyakitnya. Bentuk bentuk dukungan yang diberikan tidak berupa saran, nasehat, atau support saja, namun berupa tindakan nyata dengan mengontrol, menjadwal, dan mendampingi ketika menjalani serangkaian pengobatan.

Dari uraian di atas maka peneliti berpendapat dukungan keluarga terhadap partisipan menjalani POPM filariasis sangat mempengaruhi meningkatkan kesehatan partisipan dalam menjalani hidupnya sehari-hari.

\section{Mengetahui Adaptasi Interdependensi dalam Menjalani POPM}

Hasil penelitian yang berkenaan dengan adaptasi interdependensi dalam menjalani POPM dengan tema bahwa adanya penerimaan dan dukungan oleh masyarakat terhadap partisipan, dimana masyarakat setempat selalu melibatkan partisipan dan mendukung untuk kesembuhan partisipan, tidak mengucilkan dan menghargai.

Hal ini bertolak belakang dengan penelitian yang dilakukan oleh Muhammad (2019) dimana menunjukkan bahwa pengetahuan masyarakat Desa Matang Pelawi tentang penyakit filariasis dan pencegahannya, sebagian sudah paham, sebagian masyarakat lainnya kurang mengerti tentang penyebab, penularan, tanda dan gejala, pencegahan dan pengobatannya. Sikap masyarakat tentang penyakit filariasis, ada yang menganggap penyakit medis karena dapat mengenai siapa saja dan ada juga yang menganggap penyakit 
non medis atau karena hal gaib/mistis. Sebagian masyarakat bersikap negatif dengan mengejek, menghina dan menginginkan agar penderita filariasis diasingkan dari desa mereka karena dapat membawa musibah buruk bagi warga lainnya. Tindakan masyarakat sebagian paham tentang penyakit filariasis, dengan melakukan pencegahan seperti menjaga kebersihan lingkungan tempat tinggal, tidur menggunakan kelambu, dan minum obat pada Bulan Eliminasi Kaki Gajah (BELKAGA) pada bulan Oktober setiap tahunnya.

Teguh yaitu pendidikan, pengetahuan, dan akses ke fasilitas kesehatan. Variabel yang paling besar pengaruhnya terhadap persepsi masyarakat tentang filariasis adalah variabel pengetahuan, kedua variabel pendidikan, dan ketiga variabel akses ke pelayanan kesehatan. Variabel pengetahuan mempunyai nilai $\mathrm{OR}=14,750$ artinya masyarakat yang berpengetahuan baik berpeluang memiliki persepsi yang baik tentang filariasis 14,7 kali lebih tinggi dibandingkan masyarakat yang berpengetahuan kurang (Silalahi, 2019).

Dari uraian di atas peneliti berasumi, bahwa sikap masyarakat terhadap klien filariasis tergantung budaya, pemahaman terkait filariasis, pendidikan sangat mempengaruhi hubungan klien filariasis dalam berinteraksi dalam masyrakat. Semakin besar dukungan dari masyarakat akan membuat klien filaraisis mudah dalam menjalani pengobatan, karena klien merasa dihargai, diperhatikan dan tidak dikucilkan dalam hidup bermasyarakat.

Dalam penelitian ini, peneliti menemukan beberapa hambatan dalam penelitian ini diantaranya merupakan penelitian kualitatif perdana/pemula bagi peneliti sendiri, jarak rumah antar partisipan, kurangnya referensi terkait buku dan jurnal pengalaman klien filariasis, khususnya tentang klien filariasis dalam menjalani POPM, kendala dilapangan banyak partisipan yang tidak mau diwawancarai dengan berbagai alasan, apalagi di saat melakukan penelitian dalam keadaan COVID-19 dan juga terkait setiap isu setiap orang harus divaksin.

\section{SIMPULAN}

Penelitian ini mendapatkan sembilan tema, yaitu; mendapatkan manfaat simptomatik, kemudahan finansial dan akses pengobatan, ketidakpatuhan menjalankan POPM, mengkombinasikan dengan terapi komplementer, keterbatasan aktivitas, merasakan kelelahan, menangani gejala akut dengan mencari pengobatan medis dan alternatif, menerima keadaan sakit dengan segala keterbatasan, peran caregiver dijalankan oleh anggota keluarga, dan penerimaan dan dukungan oleh masyarakat.

\section{SARAN}

Direkomendasikan kepada pihak-pihak yang terkait dengan program POPM filariasis; meningkatkan pelayanan kepererawatan komunitas, baik secara fisik, psikologis, sosiol dan ekonomi. Hasil penelitian ini diharapkan dapat dapat menambah wawasan bagi perawat khususnya ditatanan pelayanan komunitas sehingga mutu perawatan dapat ditingkatkan. Lebih dapat mengembangkan pelayanan pada klien filariasis yang tidak hanya berpusat pada pemenuhan kebutuhan fisik (POPM filariasis) namun juga perlu diperhatikan akan kebutuhan psikologis. Pengetahuan, wawasan serta keterampilan perawat dalam memberikan asuhan kepesrawatan pada klien filaraiasis perlu ditingkatkan.

\section{DAFTAR PUSTAKA}

Afiyah, R. K. (2018). Dukungan Keluarga Mempengaruhi Kemampuan Adaptasi (Penerapan Model Adaptasi Roy) pada Pasien Kanker di Yayasan Kanker Indonesia Cabang Jawa Timur. Journal of Health Sciences, 10(1), 96-105. https://doi.org/10.33086/jhs.v10i1.150 
Agustini, A., \& Indrawati, F. (2020). Program Pemberian Obat Pencegahan Massal (PPOM) Filariasis. Higeia Journal of Public Health. 4(3), 423-434. https://doi.org/10.15294/higeia.v4i3.33304

Husnati, N. Y., Kustanti, A., \& Pangastuti, H. S. (2017). Hubungan antara Pengobatan Komplementer dengan Kualitas Hidup pada Pasien Diabetes Mellitus. Jurnal Keperaawran Klinis Dan Komunitas, 1(3), 173-183. https://jurnal.ugm.ac.id/jkkk/article/view/56593

Indarwati, R., Rahmawati, P. D., \& Sidhu, Y. V. (2020). Analisis Faktor yang Berhubungan dengan Kejadian Ulkus Diabetik pada Pasien DM Tipe 2 di Poli Penyakit Dalam RSUD Umbu Rara Meha Waingapu. Critical Medical and Surgical Nursing Journal, 8(2), 93-101. https://e-journal.unair.ac.id/CMSNJ/article/view/17782

Kementerian Kesehatan RI. (2018). Profil Kesehatan Indonesia Tahun 2019. Infodatin Filariasis Per Halaman.Pdf https://dinkes.acehprov.go.id/jelajah/read/2020/05/15/107/profil-kesehatan-acehtahun-2019.html

Muhammad, I. (2019). Analisis Kualitatif Perilaku Masyarakat terhadap Pencegahan Penyakit Filariasis di Desa Matang Pelawi 1. Healthcare: Jurnal Kesehatan 8(2), 0822. https://jurnal.payungnegeri.ac.id/index.php/healthcare/article/view/54

Nurjana, M. A., Anastasia, H., Chadijah, S., \& Nyoman, N. (2018). Dalam Program Pengobatan Massal Filariasis di Kabupaten Mamuju Utara Provinsi Sulawesi Barat Tahun 2015. Spirakel, $1(1), \quad 31-40$. https://ejournal2.litbang.kemkes.go.id/index.php/spirakel/article/view/1192

Profil Dinkes Pidie. (2019). Profil Pemerintah Kabupaten Pidie 2019. http://pidiekab.go.id/skpk/dinkes/profil-dinkes/

Ramadhan, N., Yulidar, Y., Nur, A., Hadifah, Z., \& Yasir, Y. (2020). Gambaran Status Endemisitas Filariasis dan Faktor yang Terkait dengan Transmisi Sesaat Pasca Survei Transmission Assessment Survey (TAS-) 1 di Kabupaten Pidie, Aceh. Media Penelitian dan Pengembangan Kesehatan, 29(4), 353-364. https://doi.org/10.22435/mpk.v29i4.2099

Reasoa, M. S., Ranimpi, Y. Y.,Kurniasari, R. M. D., \& De-Fretes, F. (2020). Respons Psikososial dan Kesejahteraan Psikologis Pasien Filariasis di Kota Ambon. Jurnal Psikologi Ulayat, 7(1) 24-37. https://doi.org/10.24854/jpu02019-230

Silalahi, R. H. (2019). Faktor-Faktor yang Memengaruhi Persepsi Masyarakat tentang Filariasis di Desa Juma Teguh Kecamatan Siempat Nempu Kabupaten Dairi. Jurnal Kesehatan Bukit Barisan, 2(4), 71-87. http://ejournal.akperkesdambinjai.ac.id/index.php/Jur_Kes_Dam/article/view/63

Tallan, M. M., Mau, F., \& Bulu, A. K. (2019). Pengetahuan, Sikap, dan Tindakan Masyarakat tentang Filariasis Limfatik di Kecamatan Kodi Balaghar, Kabupaten Sumba Barat Daya. ASPIRATOR-Journal of Vector-Borne Disease Studies, 11(1), 2936. https://ejournal2.litbang.kemkes.go.id/index.php/aspirator/article/view/207

Ulfiana, H. R., \& Indarjo, S. (2021). Efikasi Diri pada Penderita Positif Filariasis di Kota Pekalongan. Indonesian Journal of Public Health and Nutrition. 1(2), 234-243. https://journal.unnes.ac.id/sju/index.php/IJPHN/article/download/45398/19532

World Health Organization. (2017). Guideline: Alternative Mass Drug Administration Regimens to Eliminate Lymphatic Filariasis. In Guideline: Alternative Mass Drug Administration Regimens to Eliminate Lymphatic Filariasis. http://www.ncbi.nlm.nih.gov/pubmed/29565523 